\title{
Evaluation of a health education program for improving uptake of HIV self-testing by men in Rwanda: a pilot pragmatic randomized control trial
}

\author{
Tafadzwa Dzinamarira ${ }^{1,2^{*}}$ (D) Claude Mambo Muvunyi ${ }^{2}$ and Tivani Phosa Mashamba-Thompson 1,3,4
}

\begin{abstract}
Background: Health education interventions tailored to suit men have the potential to improve health outcomes for this underserved population. HIV self-testing (HIVST) is a promising approach to overcoming challenges associated with low HIV testing rates among men. The primary objective of this study is to assess the feasibility of conducting a definitive trial to determine the effectiveness of a locally adapted and optimized health education program (HEP) on the uptake of HIVST among men in Kigali, Rwanda.
\end{abstract}

Methods: This study employs a pilot pragmatic randomized controlled trial to evaluate an HIVST HEP for men. Participants were randomized to the intervention (HEP) arm or to the control arm. In the intervention group, the adapted HEP was administered in addition to routine health education. In the non-intervention group, only routine health education was offered. Participant data was collected first upon recruitment and then after 3 months' follow-up using interviewer-administered questionnaires.

Results: There was a 100\% response rate at enrollment and no loss to follow-up at exit. There was significant association between the study arm and knowledge of HIVST. Participants in the control arm had a mean knowledge score of $67 \%$ compared to $92 \%$ among participants in the intervention arm. There was an association between the study arm and HIVST uptake: $67 \%$ of the study participants in the intervention arm self-reported HIVST uptake compared to $23 \%$ of the participants in the control arm.

Discussion: This pilot study demonstrates the feasibility of a larger trial to assess the effectiveness of an HEP intervention on uptake of HIVST among men. We found preliminary evidence of increased uptake of HIVST in the intervention group.

Trial registration: Pan African Clinical Trial Registry PACTR201908758321490. Registered on 8 August 2019.

Keywords: Health education, Men, HIV self-testing

\section{Key messages regarding feasibility}

*Correspondence: anthonydzina@gmail.com

${ }^{1}$ Department of Public Health Medicine, School of Nursing and Public Health, University of KwaZulu-Natal, Durban 4001, South Africa

Full list of author information is available at the end of the article
- The pilot study proved a larger trial to implement and assess effectiveness of the health education program intervention is feasible. However, the Hawthorne effect cannot be excluded for this pilot study as use self-report data to guide on feasibility of this trial. original author(s) and the source, provide a link to the Creative Commons licence, and indicate if changes were made. The images or other third party material in this article are included in the article's Creative Commons licence, unless indicated otherwise in a credit line to the material. If material is not included in the article's Creative Commons licence and your intended use is not permitted by statutory regulation or exceeds the permitted use, you will need to obtain permission directly from the copyright holder. To view a copy of this licence, visit http://creativecommons.org/licenses/by/4.0/. The Creative Commons Public Domain Dedication waiver (http://creativeco mmons.org/publicdomain/zero/1.0/) applies to the data made available in this article, unless otherwise stated in a credit line to the data. 
- The intervention can be implemented and assessed in a larger randomized controlled trial. There was 100\% enrollment and no loss to follow-up for the pilot study. Participants in the intervention group had a more favorable outcome with regard to uptake of HIV self-testing.

- The design of the main study will require a more objective tool or confirmation for the primary outcome; uptake of HIV self-testing.

\section{Background}

The Joint United Nations Programme on HIV and AIDS (UNAIDS) reports that in $2018,21 \%$ of people living with HIV/AIDS were unaware of their status [1]. Despite the major success reported in the HIV care continuum cascade, knowledge of one's status remains an important first step to accessing treatment $[1,2]$. Rwandan health system generally appears to be stemming the tide of the HIV/AIDS epidemic with a reported decline in HIV prevalence to below 3\% [3], from 13\% in the 1990s [4]. Major success has been reported in the HIV response in Rwanda; however, available evidence shows a gap between the current situation and the UNAIDS 90-90-90 target for 2020 [3]. Addressing male aversion to HIV testing services (HTS) has remained a priority in Rwanda's HIV program for more than two decades now $[4,5]$, since a gap in testing rates between men and women has been consistently observed in national surveys conducted in 2005 [6], 2010 [7], 2015 [8], and 2019 [3].

Men have been reported to fear confidentiality breaches due to not trusting healthcare workers [9-11], so HIV self-test kits enable individuals to test themselves for HIV in their home, without the presence of healthcare providers [12, 13]. HIV self-testing (HIVST), therefore, may potentially benefit men who routinely experience significant breaches to health care anonymity and confidentiality [14-16]. While a number of benefits are associated with HIVST, long-standing barriers to accessing HTS are likely to remain pertinent [17]. A qualitative study conducted on health officials, community health workers, and persons living with HIV in South Africa revealed that people who do not feel "ready" to know their status, who worry about HIV-related stigmas, or who fear dying of AIDS will possibly still be reluctant to be tested, even when self-test kits become available [18]. The main reported concerns about HIVST uptake also include a general lack of counseling, accuracy hindrances and a potential for the coercive use of self-testing devices $[16,18,19]$. Provision of health education has been recommended to ensure the proper uptake of HIVST [17, $20,21]$.
Health education is one of the main strategies that can be used to ensure the effective implementation of health promotion and disease prevention programs [22]. Major success has been reported when health education strategies are tailored to their target population [22]. Delivery models for health education vary between classes, workshops, webinars, lectures, and courses [23], which present information through audiovisual and computerbased supports like projectors, slides, books, videos, posters, CDs, websites, pictures and software programs [24]. A key characteristic of a successful health education strategy is a carefully planned learning activity that is well informed and aimed at increasing the skills and knowledge of the participants [25]. There is global evidence that health education programs improve health outcomes. Health education interventions about voluntary circumcision and HIV among youth in Kenya [26], male involvement in family planning in Malawi [27] and India [28], and male involvement in maternity care in South Africa [29], Nepal [30], and Pakistan [31] all reported improved health outcomes.

This study is part of a larger study [32] aimed at employing an HEP for improving men's uptake of HIVST. In the earlier phases of this study, we conducted interviews with key stakeholders to assess their perspectives on the implementation and upscaling of HIVST in Rwanda [33]. A cross-sectional study was employed to assess awareness and acceptability of HIVST among men in Kigali, Rwanda [34]. Guided by the findings from the interviews with stakeholders and from the cross-sectional study, we employed the nominal group technique in a co-creation workshop involving key stakeholders in the HIV response in Rwanda to design the health education program. A detailed account of the methodology and the results of the workshop are fully described in a manuscript submitted elsewhere [35]. A two-step process was followed to identify priority barriers to men's uptake of current HTS and to co-create, with key stakeholder, an HEP for HIVST that would address these barriers. The outcome was a male-tailored health education program aimed at improving HIVST uptake. The current study assesses the feasibility of conducting a larger trial. This trial would evaluate the locally adapted and optimized health education program designed to improve the uptake of HIVST among men in Kigali, Rwanda.

\section{Methods \\ Design}

This study is part of a multi-phase $\mathrm{PhD}$ project; protocol for the main study is published elsewhere [32]. The research group conducted a two-arm pilot pragmatic randomized control trial. This trial was registered in the Pan African Clinical Trial Registry, 
PACTR201908758321490), https://pactr.samrc.ac.za/ TrialDisplay.aspx?TrialID $=8310$.

In this trial, participants were randomized to the health education program arm (HEP) or to the control arm. In the intervention group, the adapted HEP was administered in addition to routine health education. Data collection occurred through interviewer-administered questionnaires that were transferred onto mobile tablet devices using the pre-programmed study software, Open Data Kit (ODK).

\section{Study setting}

The University Teaching Hospital of Kigali (CHUK) was purposively selected to pilot the implementation the HEP intervention. CHUK is the largest hospital located in Nyarugenge District, Kigali City. It is also the largest referral hospital in the country. Trained health professionals introduced the intervention in the outpatient department, as outpatients are not expected have critical conditions that would affect their ability to take part in the HEP or the interviewer-administered questionnaire.

\section{Inclusion criteria}

This study included participants who met the eligibility criteria below:

- Adult male, 18 years and older

- Unknown HIV status

- Is visiting the study-selected health facility during the enrolment period

- Is willing to be followed up with three months postenrolment

\section{Exclusion criteria}

This study excluded participants who met the eligibility criteria below:

- Female gender

- Men younger than 18 years of age

- Known HIV status

- Is unwilling to be followed up with three months post-enrolment

\section{Control}

The control group received routine health education on HIV/AIDS and sexual health. This was delivered in Kinyarwanda, the local language, by trained health professionals. The sessions lasted approximately $45 \mathrm{~min}$.

\section{Intervention}

The intervention, an HEP, was an interactive, structured curriculum containing eight modules with information on health locus of control, HIV etiology and transmission, diagnosis, status disclosure benefits, and care and treatment services. The modules also included an overview of the background of HIVST and the testing procedure. The contents of the HEP were validated by the HIV Division in the Rwanda Biomedical Center, Ministry of Health. The HEP was delivered through face-toface communication and using information education communication materials. The HEP was taught in a maximum of $1 \mathrm{~h}$. Two health professionals at the study site were trained to deliver the HEP in Kinyarwanda. Follow-up interviews were scheduled for 3 months post-enrolment.

\section{Outcomes}

\section{Primary outcome(s)}

The main outcome of this study is feasibility of a larger RCT trial measured by recruitment into the study and uptake of HIVST. The feasibility criteria were measured by number of participants retained at follow-up for an exit interview. For the purposes of this trial, uptake is defined as self-reported use of the HIVST kit at the follow-up interview.

\section{Secondary outcome(s)}

This study also assessed HIV diagnosis among participants, linkage to care among men who tested HIV positive, 3-month repeat tests for men who tested HIV negative, and HIV status disclosure to sexual partner(s) after HIV self-testing.

\section{Hypothesis of the larger pragmatic trial}

The locally adapted and optimized health education program will improve the uptake of HIVST in the intervention arm as compared to routine health education in the control arm among men in Kigali, Rwanda.

\section{Sample size}

For this study, we recruited 60 men who were randomized in a 1:1 ratio between the intervention and control groups. Given that this was a pilot study, we followed the recommendation of Browne et al. [36] to determine the sample size based on the estimated parameter of 30 participants.

\section{Recruitment of participants}

The study's population was men attending the study site who self-reported unknown HIV status at the time of enrolment, were above the age of 18 years, and 
were residents in Kigali Province during the period of March-July 2020. The target population was men who were visiting the study's health facility as clients, were accompanying or visiting relatives, or were visiting for other reasons.

\section{Randomization procedure and blinding}

We employed simple randomization using a randomization table created by a computer software program (RALLOC, STATA) and an independent statistician. The researcher kept sequentially numbered allocation codes in sealed envelopes. Each eligible participant collected an envelope containing their allocation after baseline data has been completed. This method prevented participants and recruiters from knowing the study group to which the next participant would be assigned [37]. We chose this approach, as it helped to ensure that a participant's decision to provide informed consent, or a recruiter's decision to enroll a participant, was not influenced by knowledge of the group to which they would be allocated if they joined the trial $[37,38]$. We conducted an openlabel trial, meaning participants were aware of their study arm.

\section{Data collection methods}

At enrolment, participants' baseline data was captured using an interviewer-administered questionnaire (Supplementary File 1). We pilot-tested the data collection tool on ten non-survey participants to assess clarity of questions, their reliability, and their validity. Participants in the control group received routine health education on HIV/AIDS and sexual health. In addition to routine health education, participants in the intervention group received the HEP (Supplementary File 2). At the followup interview, we employed an interviewer-administered questionnaire (Supplementary File 3) for data collection. Quality assurance during the trial was secured through the effective supervision of the trained data collectors. The first (TD) and second (CMM) authors were responsible for providing supervision to the two research assistants during enrolment, baseline data collection, intervention administration, and follow-up interview data collection. All data was captured on a pre-programmed study software, ODK, with transmission after each participant. Knowledge, attitudes, and practice were assessed using a set of questions: knowledge (16 questions), attitude (12 questions), and practice (11 questions)

\section{Data management}

In this study, all data was entered electronically. The data entry screens resembled the paper forms approved by the institutional review boards. We ensured data integrity through a variety of mechanisms. Validation tools were built into the tablet data collection system to minimize data entry errors and to encourage proper form completion. Pre-defined values (code sets) for categorical data, range restrictions for numeric data, and logic checks were used to restrict the type of data and minimize data entry errors. Entry of data in the key fields was required to ensure completeness, and skip patterns were used to prevent irrelevant data entry. The software was equipped with error messages and caution notices that would be triggered if data collection staff were to enter faulty data. All the study's paper forms were kept in locked cabinets, and access to the study data was restricted. A password system was utilized to control access to the tablets used for data collection.

\section{Data analysis}

Feasibility outcomes, determined by recruitment and retention in the trial were calculated by using raw count numbers and percentages. A quality score was calculated for each of the knowledge, attitude, and practice domains. The three domain scores were independent and hence not aggregated into a single quality score. The domain scores were calculated by totaling the scores of the individual items in a domain and by scaling the total as a percentage of the maximum possible score for that domain. The scaled domain score $=$ (obtained score minimum possible score)/(maximum possible score minimum possible score). We used the chi-square test to determine association between categorical dependent and categorical independent variables. We used the Student $t$ test to determine association between quantitative dependent and categorical independent variables. All statistical tests were performed in the STATA software package. A $p$ value $<0.05$ was considered significant.

\section{Results}

\section{Participant demographic and sexual health history characteristics}

A total of 60 participants, randomized into either the control arm (50\%) or the intervention arm (50\%), were enrolled for this pilot study. There was a $100 \%$ response rate at enrolment and no loss to follow-up at exit (Fig. 1). The mean age of the participants was 32 years. Nineteen percent was enrolled from Gasabo District, $32 \%$ from Nyarugenge District, and 28\% from Kicukiro District. Twenty-eight percent were single, $50 \%$ were married, and the rest were either cohabiting, widowed, or divorced. More details on demographic characteristics are available in Table 1.

All the participants reported to have had sexual intercourse. The majority (93\%) were heterosexual, while $7 \%$ were homosexual. The median number of each participant's sexual partners over last 12 months was one, 


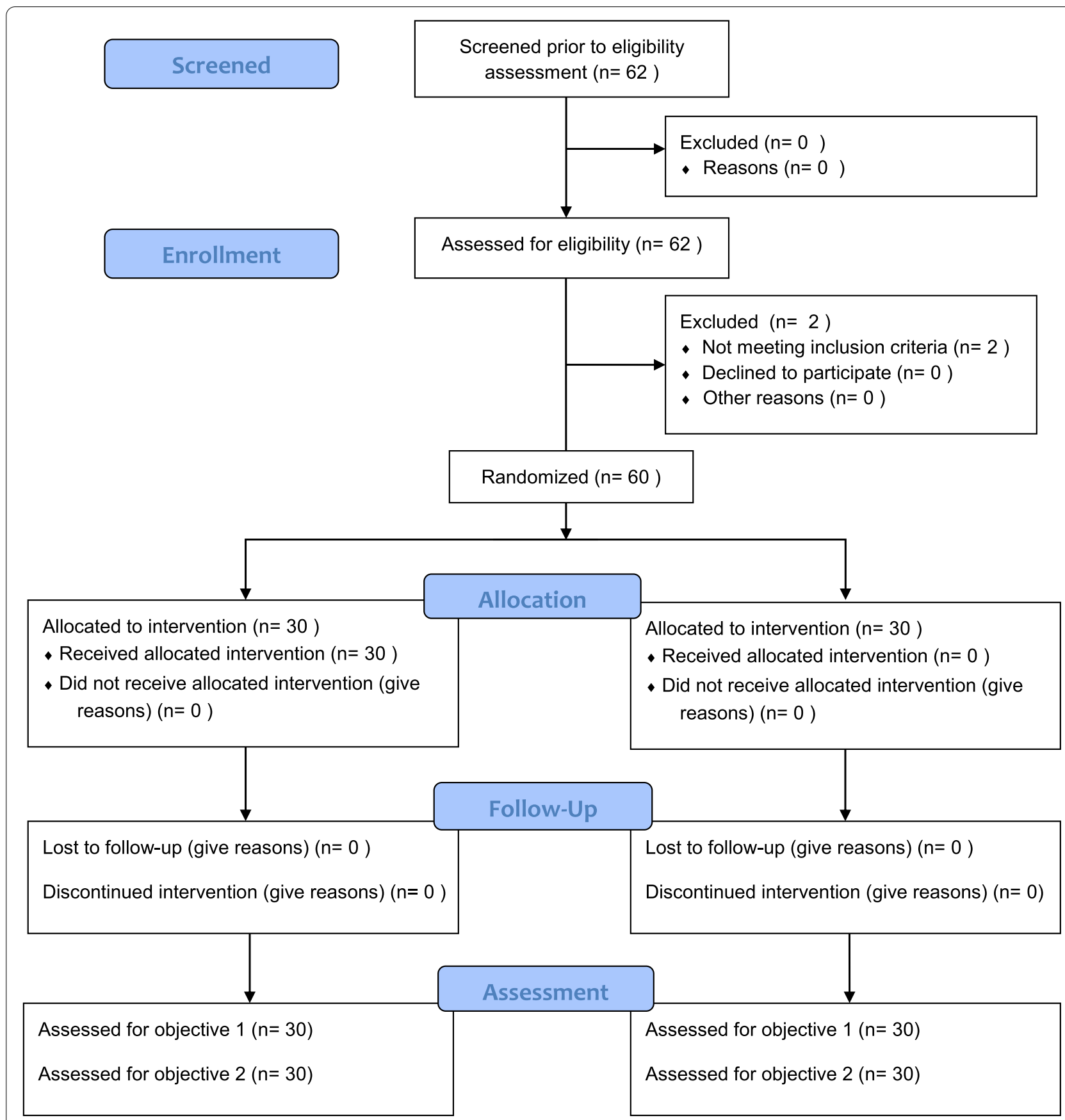

Fig. 1 Flow diagram

ranging from one to six partners. More details are presented on participant sexual characteristics in Table 2.

\section{Knowledge, attitude, and perception toward HIVST}

There was a significant difference in the change of knowledge level between the control and intervention, the control had an average increase in the knowledge score of 7.1 compared to the intervention group which had an average increase of 30.6. There was a significant difference in the change of attitude level between the control and intervention; the control had an average decrease in the attitude score of 2.1 compared to the intervention group which had an average increase of 14.8. There was a significant difference in the change of perception level between the control and intervention; the control had an average decrease in the perception score of 4.9 compared 
Table 1 Participant demographic characteristics

\begin{tabular}{ll}
\hline Variable & Response $(\boldsymbol{n}=\mathbf{6 0})$ \\
\hline Age in years, mean (SD) & $32.0(9.8)$ \\
Education level, $n$ (\%) & \\
Primary & $6(10)$ \\
Secondary & $28(47)$ \\
Tertiary & $25(42)$ \\
Did not attend school & $1(2)$ \\
Income, $n$ (\%) & \\
Self-employed & $22(37)$ \\
Professional & $23(38)$ \\
Unemployed & $15(25)$ \\
District, $n$ (\%) & \\
Gasabo & $24(19)$ \\
Nyarugenge & $19(32)$ \\
Kicukiro & $17(28)$ \\
Marital status, $n$ (\%) & \\
Single & $17(28)$ \\
Cohabitation & $8(13)$ \\
Widowed & $4(7)$ \\
Married & $30(50)$ \\
Divorced & $1(2)$ \\
Religion, $n$ (\%) & \\
Christian & \\
Muslim & $49(82)$ \\
Other specify & $10(17)$ \\
\hline
\end{tabular}

to the intervention group which had an average increase of 17.7. Details on mean knowledge score changes are presented in Table 3.

\section{Self-reported HIV testing at follow-up visit}

There was an association between having tested for HIV and the study arm $(p<0.05)$ : in the intervention arm, $67 \%$ of the participants had received an HIV test; in the control arm, $27 \%$.

There was no association between the study arm and the following: the number of times a participant reported to have been tested for HIV at the exit, the place the first HIV test was performed, the place last HIV test was performed, and the first HIV test result $(p>0.05)$. More details are presented in Table 4.

\section{Discussion}

This study has determined the feasibility of conducting a larger trial to evaluate the effectiveness of a maletailored health education program on the uptake of HIVST among men in Kigali, Rwanda. Men's engagement in health services, particularly HIV testing services, is a priority in Rwanda's public health agenda [8]. To address this priority, key stakeholders in HIV
Table 2 Sexual health history and health seeking behavior

\begin{tabular}{|c|c|}
\hline Variable & Response \\
\hline \multicolumn{2}{|l|}{ Ever had sexual intercourse, $n(\%)$} \\
\hline Yes & $60(100)$ \\
\hline \multicolumn{2}{|l|}{ Sexual preference, $n(\%)$} \\
\hline Heterosexual & $56(93)$ \\
\hline Homosexual & $4(7)$ \\
\hline $\begin{array}{l}\text { Number of different sexual partners last } 12 \text { months, median } \\
\text { (range) an (SD) }\end{array}$ & $1(1-6)$ \\
\hline \multicolumn{2}{|l|}{ Ever paid for sex 1 month ago, $n$ (\%) } \\
\hline Yes & $19(32)$ \\
\hline \multicolumn{2}{|l|}{ Circumcised, $n(\%)$} \\
\hline Yes & $30(50)$ \\
\hline \multicolumn{2}{|l|}{ Know condom use, $n(\%)$} \\
\hline Yes & $60(100)$ \\
\hline \multicolumn{2}{|l|}{ Frequency condom use last 12 months, $n(\%)$} \\
\hline Never & $12(20)$ \\
\hline Rarely & $48(80)$ \\
\hline \multicolumn{2}{|l|}{ Risk of HIV, $n(\%)$} \\
\hline Fairly high & $6(10)$ \\
\hline Low & $14(23)$ \\
\hline Very low & $40(67)$ \\
\hline \multicolumn{2}{|l|}{ Last visit to health facility, $n$ (\%) } \\
\hline Never & $18(30)$ \\
\hline $1-3$ months ago & $22(37)$ \\
\hline $4-6$ months ago & $1(2)$ \\
\hline $6-12$ months ago & $2(3)$ \\
\hline More than a year ago & $17(28)$ \\
\hline \multicolumn{2}{|l|}{ Last 3 months sick, $n$ (\%) } \\
\hline Consultation with qualified medical practitioners & $18(30)$ \\
\hline Consultation with community health worker & $22(37)$ \\
\hline Consultation with traditional health care practitioners & $1(2)$ \\
\hline Consultation with over the counter drug sellers & $2(3)$ \\
\hline Consultation with self and other family members & $17(28)$ \\
\hline
\end{tabular}

response in Rwanda have called for swift implementation and evaluation of HIVST intervention [33]. This is consistent with the World Health Organization's recommendation to evaluate the interventions used to upscale HIVST uptake among different groups in terms of gender, socio-economic status, and education level [39].

In this pilot study, there was $100 \%$ recruitment at enrolment and no loss to follow-up at exit. There was a marked difference in mean knowledge among the two different arms of the study, with a higher mean knowledge (92\%) in the arm that received the intervention compared to a lower mean knowledge (62\%) in the control arm. A systematic review by Pant Pai et al. reveals that knowledge on HIVST drives the motivation that 
Table 3 Analysis of change in knowledge, attitude, and perceptions toward HIVST from enrolment to follow-up across study groups

\begin{tabular}{llll}
\hline Variable & Control & Intervention & Difference \\
\hline Knowledge score, mean difference\% $(95 \% \mathrm{Cl})$ & $7.1(2.5-11.7)$ & $30.6(23.5-37.8)$ & $23.5(15.2-31.9)$ \\
Attitude score, mean difference\% $(95 \% \mathrm{Cl})$ & $-2.1(-7.6-3.5)$ & $14.8(5.5-25.3)$ & $16.9(6.3-27.6)$ \\
Perception score, mean difference\% $(95 \% \mathrm{Cl})$ & $-4.9(-10.5-0.6)$ & $17.7(0.9-11.9)$ & $22.6(13.4-31.9)$ \\
\hline
\end{tabular}

Table 4 Self-reported HIV testing at follow-up

\begin{tabular}{|c|c|c|c|}
\hline Variable & Control & Intervention & Difference $\%(95 \% \mathrm{Cl})$ \\
\hline \multicolumn{4}{|c|}{ Ever tested for HIV, $n$ (\%) } \\
\hline No & $22(73)$ & $10(33)$ & $34(22-46)$ \\
\hline Yes & $8(27)$ & $2067)$ & Ref \\
\hline \multicolumn{4}{|c|}{ Number of times have you been tested for HIV, $n$ (\%) } \\
\hline 1 & $5(28)$ & $13(72)$ & $6(-3-15)$ \\
\hline 2 & $2(22)$ & $7(78)$ & Ref \\
\hline \multicolumn{4}{|c|}{ Where was the first HIV test done since our last discussion? } \\
\hline Home & $7(26)$ & $20(74)$ & $74(58-90)$ \\
\hline Health facility & $1(100)$ & - & Ref \\
\hline \multicolumn{4}{|c|}{ Last HIV test done since our last discussion, $n(\%)$} \\
\hline Home & $1(25)$ & $3(75)$ & $8(-9-25)$ \\
\hline Health facility & $2(33)$ & $4(67)$ & $30(13-47)$ \\
\hline \multicolumn{4}{|c|}{ First HIV test result, $n(\%)$} \\
\hline Positive & - & $1(100)$ & Ref \\
\hline Negative & $8(30)$ & $19(70)$ & $34(22-46)$ \\
\hline
\end{tabular}

improves the uptake of HIVST [40]. This has also been evidenced by a study in South Africa, after the introduction of an HIVST network, that helped educate men about HIVST [41]. Our earlier work on the awareness and acceptability of HIVST in Rwanda found low awareness and high acceptability of HIVST [34]. The results of the current pilot study reveal a need for a health education intervention to improve men's knowledge on HIVST intervention. Studies conducted in Botswana [42] and Tanzania [21] have revealed similar gaps in the knowledge of HIVST among men. An HIVST strategy that addresses the concerns of the male population is likely to be feasible for and relevant to the Rwandese male population. This study found an association between attitude toward HIVST and uptake; in the control arm, participants showed a mean attitude score of $65 \%$; in the intervention arm, $84 \%$. Similar findings were reported among men who have sex with men in the Philippines after an introduction of an HIVST strategy focused and targeted on them and tailored for men [43]. These findings are promising concerning the establishment of a full-scale, larger trial for the intervention. At present, there is limited evidence on the effectiveness of health education programs on HIVST uptake among men. However, a number of studies have drawn conclusions on the potential of education programs to improve HIVST uptake among priority populations, including men. A study on oral HIVST uptake among men in Uganda revealed that the participants could not comprehend how HIV testing could be done without using a blood sample. The study revealed a need to intensify health education about oral HIVST to improve uptake [44]. A study conducted in Nepal recommended the use of a one-to-one education approach in providing HIVST information [45].

A major strength of this study is its implementation of the intervention in a pragmatic approach. Consistent with the nature of pragmatic trials, this study's findings are applicable to routine practice. However, this study has its limitations. Though recruited through methods designed to generate a representative sample, as this is a pilot study, the sample is unlikely to be representative of all men in Kigali. Additionally, the sample was largely young with a mean age of 32 years, which indicates an underrepresentation of older men. Since this was a pilot study, the sample size determination was small. Some inferential statistics were performed in the study to only get an insight of variables that are likely to have an association; however, some if not all the statistical tests were subject to huge bias because of the small sample size used in performing these tests. It is therefore apparent that some statistical significance association $(p<0.05)$ observed in the study only means that there is a possibility of an association that can only be concluded or confirmed by the main study. Therefore, clinical outcomes from this feasibility trial are suggestive rather than definitive. While the results from this study will add to the ever-growing data that HIVST would upscale HIV testing, the limitations of the study warrant larger indepth, randomized controlled trials for understanding the impact of the health education program on HIVST uptake.

\section{Conclusion}

This pilot study demonstrates the feasibility of a larger trial to assess the effectiveness of a health education program intervention on the uptake of HIVST among men. We found preliminary evidence of an increased uptake of HIVST in the intervention group. 


\section{Abbreviations}

HIVST: HIV self-testing; HEP: Health Education Program; ODK: Open Data Kit.

\section{Supplementary Information}

The online version contains supplementary material available at https://doi. org/10.1186/s40814-021-00940-x.

\section{Additional file 1.}

Additional file 2.

Additional file 3.

\section{Acknowledgements}

This study was supported by the CIHR Canadian HIV Trials Network (CTN 222). Prof Tivani P. Mashamba-Thompson is supported by CTN Postdoctoral Fellowship Award.

\section{Authors' contributions}

Tafadzwa Dzinamarira_conception; data collection; data analysis; writing. Claude Mambo Muvungi-data collection; data analysis; writing. Tivani P Mashamba Thompson-conception; writing; supervision. The authors read and approved the final manuscript.

\section{Funding}

The University of KwaZulu-Natal, College of Health Sciences PhD Scholarship (award number: 641581) supported this study.

\section{Availability of data and materials}

The raw data analyzed in this study is available upon reasonable written request submitted to the corresponding author

\section{Declarations}

\section{Ethics approval and consent to participate}

This study was conducted in accordance with the Helsinki Declaration [46]. It was also ethically reviewed and approved by four institutional review boards: Rwanda National Ethics Committee (approval number: 332/RNEC/201), University Teaching Hospital of Kigali Ethics Committee (approval number: EC/CHUK/0111/2019), Rwanda Military Hospital Institutional Review Board (approval number: RMH IRB/036/2019), and the University of KwaZulu Natal Biomedical Research Ethics Committee (approval number: BE/280/19).

\section{Consent for publication}

Not applicable

\section{Competing interests}

The authors declare that they have no competing interests.

\section{Author details}

${ }^{1}$ Department of Public Health Medicine, School of Nursing and Public Health, University of KwaZulu-Natal, Durban 4001, South Africa. ${ }^{2}$ College of Medicine and Health Sciences, University of Rwanda, Kigali, Rwanda. ${ }^{3} \mathrm{CIHR}$ Canadian HIV Trials Network, Vancouver, BC, Canada. ${ }^{4}$ Faculty of Health Sciences, University of Pretoria, Pretoria, Pretoria, South Africa.

Received: 10 Auqust 2020 Accepted: 29 October 2021

Published online: 12 November 2021

\section{References}

1. UNAIDS. Factsheet: global AIDS update. UNAIDS Geneva; 2019. Available at https://www.unaids.org/sites/default/files/media_asset/UNAIDS_FactS heet_en.pdf Accessed on 13 July 2020.

2. Justman J, Hoos D, Kalton G, Nyirenda R, Moyo C, Mugurungi O. Real progress in the HIV epidemic: PHIA findings from Zimbabwe, Malawi and Zambia. Conf Retrovirus Opportunistic Infect. 2017:13-6.
3. ICAP. Summary Sheet: Preliminary Findings: Rwanda population-based HIV Impact Assessment RPHIA 2018-2019. 2019. Available at https:// phia.icap.columbia.edu/countries/rwanda/. Accessed on 1 July 2020

4. Vogel L. Rwanda turning tide on HIV/AIDS. 2011;183(12):E781. doi: https://doi.org/10.1503/cmaj.109-3938 Accessed on 12 July 2020

5. Kayirangwa E, Hanson J, Munyakazi L, Kabeja A. Current trends in Rwanda's HIV/AIDS epidemic. Sex Transm Infect. 2006;82(suppl 1):i27-31. https://doi.org/10.1136/sti.2006.019588.

6. Institut National de la Statistique du Rwanda - INSR, ORC Macro. Rwanda Demographic and Health Survey 2005. Calverton: INSR and ORC Macro; 2006.Available at https://dhsprogram.com/publications/ publication-FR183-DHS-Final-Reports.cfm Accessed on 13 July 2020

7. National Institute of Statistics of Rwanda - NISR, Ministry of Health $\mathrm{MOH} /$ Rwanda, ICF International. Rwanda Demographic and Health Survey 2010. Calverton: NISR/Rwanda, $\mathrm{MOH} /$ Rwanda, and ICF International; 2012. Available at https://dhsprogram.com/pubs/pdf/PR7/PR7. pdf Accessed on 13 July 2020

8. National Institute of Statistics of Rwanda, Ministry of Health/Rwanda, and ICF International. Rwanda Demographic and Health Survey 201415. Kigali: Ministry of Health/Rwanda, and ICF International; 2016. Available at https://www.dhsprogram.com/pubs/pdf/FR316/FR316.pdf Accessed on 13 July 2020

9. WHO. HIV Self-Testing Strategic Framework: A Guide For Planning, Introducing And scaling up HIV testing services. Geneva: World Health Organization; 2018. Available at https://apps.who.int/iris/bitstream/ handle/10665/275521/9789241514859-eng.pdf?ua=1 Accessed on 13 July 2020.

10. Schnall R, Carballo-Diéguez A, Larson E. Can the HIV home test promote access to care? Lessons learned from the in-home pregnancy test. AIDS Behav. 2014;18(12):2496-8. https://doi.org/10.1007/ s10461-014-0798-8.

11. Iwuji CC, Orne-Gliemann J, Larmarange J, Okesola N, Tanser F, Thiebaut $\mathrm{R}$, et al. Uptake of home-based HIV testing, linkage to care, and community attitudes about ART in rural KwaZulu-Natal, South Africa: descriptive results from the first phase of the ANRS 12249 TasP clusterrandomised trial. PLoS Med. 2016;13(8):e1002107. https://doi.org/10. 1371/journal.pmed.1002107.

12. Bigogo G, Amolloh M, Laserson KF, Audi A, Aura B, Dalal W, et al. The impact of home-based HIV counseling and testing on care-seeking and incidence of common infectious disease syndromes in rural western Kenya. BMC Infect Dis. 2014;14(1):376. https://doi.org/10.1186/ 1471-2334-14-376.

13. WHO. Guidelines on HIV self-testing and partner notification: supplement to consolidated guidelines on HIV testing services. Geneva: World Health Organization; 2016. Report No.: 9241549866. Available at https://www.who.int/hiv/pub/vct/hiv-self-testing-guidelines/en/ Accessed on 10 July 2020

14. Hurt CB, Powers KA. Self-testing for HIV and its impact on public health. Sex Transm Dis. 2014;41(1):10. https://doi.org/10.1097/OLQ.0000000000 000076.

15. Kyaddondo D, Wanyenze RK, Kinsman J, Hardon A. Home-based HIV counseling and testing: client experiences and perceptions in Eastern Uganda. BMC Public Health. 2012;12(1):966. https://doi.org/10.1186/ 1471-2458-12-966.

16. Dzinamarira T, Pierre G, Rujeni N. Is HIV self-testing a potential answer to the low uptake of HIV testing services among men in Rwanda? Perspectives of Men Attending Tertiary Institutions and Kimisagara Youth Centre in Kigali, Rwanda. Global J Health Sci. 2019;11(11). https://doi.org/10. 5539/gjhs.v11n11p67.

17. Dzinamarira T. The call to get more men tested for HIV: a perspective on what policy makers need to know for implementing and scaling up HIV self-testing in Rwanda. Global J Health Sci. 2019;11(10). https://doi.org/ 10.5539/gjhs.v11n10p29.

18. van Heerden A, Harris DM, van Rooyen H, Barnabas RV, Ramanathan N, Ngcobo N, et al. Perceived mHealth barriers and benefits for home-based HIV testing and counseling and other care: qualitative findings from health officials, community health workers, and persons living with HIV in South Africa. Soc Sci Med. 2017;183:97-105. https://doi.org/10.1016/j. socscimed.2017.04.046.

19. Ying R, Sharma M, Celum C, Baeten JM, van Rooyen H, Hughes JP, et al. Home testing and counselling to reduce HIV incidence in a generalised 
epidemic setting: a mathematical modelling analysis. Lancet HIV. 2016;3(6):e275-82. https://doi.org/10.1016/\$2352-3018(16)30009-1.

20. Dzinamarira T, Mashamba-Thompson TP. Factors contributing toward men's engagement with HIV services: a narrative review. Global J Health Sci. 2019:11(10). https://doi.org/10.5539/gihs.v11n10p150.

21. Conserve DF, Muessig KE, Maboko LL, Shirima S, Kilonzo MN, Maman S, et al. Mate Yako Afya Yako: Formative research to develop the Tanzania HIV self-testing education and promotion (Tanzania STEP) project for men. PLoS One. 2018;13(8):e0202521. https://doi.org/10.1371/journal. pone. 0202521 .

22. Coe G, de Beyer J. The imperative for health promotion in universal health coverage. Global Health Sci Pract. 2014;2(1):10-22. https://doi.org/10. 9745/GHSP-D-13-00164.

23. Darlington EJ, Violon N, Jourdan D. Implementation of health promotion programmes in schools: an approach to understand the influence of contextual factors on the process? BMC Public Health. 2018;18(1):163. https://doi.org/10.1186/s12889-017-5011-3.

24. Springer AE, Evans AE, Ortuño J, Salvo D, Varela Arevalo MT. Health by design: interweaving health promotion into environments and settings. Front Public Health. 2017:5:268. https://doi.org/10.3389/fpubh.2017. 00268.

25. Walker LO, Kim S, Sterling BS, Latimer L. Developing health promotion interventions: a multisource method applied to weight loss among low-income postpartum women. Public Health Nurs. 2010;27(2):188-95. https://doi.org/10.1111/j.1525-1446.2010.00841.x.

26. Kibel M, Shah P, Ayuku D, Makori D, Kamaara E, Choge E, et al. Acceptability of a pilot intervention of voluntary medical male circumcision and HIV education for street-connected youth in western Kenya. J Adolesc Health. 2019;64(1):43-8. https://doi.org/10.1016/j.jadohealth.2018.07.027.

27. Shattuck D, Kerner B, Gilles K, Hartmann M, Ng'ombe T, Guest G. Encouraging contraceptive uptake by motivating men to communicate about family planning: the Malawi Male Motivator project. Am J Public Health. 2011;101(6):1089-95. https://doi.org/10.2105/AJPH.2010.300091.

28. Raj A, Ghule M, Ritter J, Battala M, Gajanan V, Nair S, et al. Cluster randomized controlled trial evaluation of a gender equity and family planning intervention for married men and couples in rural India. PLoS One. 2016;1 1(5):e0153190. https://doi.org/10.1371/journal.pone.0153190

29. Kunene B, Beksinska M, Zondi S, Mthembu N, Mullick S, Ottolenghi E, et al. Involving men in maternity care: South Africa. 2004. https://doi.org/ $10.31899 /$ rh4.1204

30. Mullany BC, Becker S, Hindin MJ. The impact of including husbands in antenatal health education services on maternal health practices in urban Nepal: results from a randomized controlled trial. Health Educ Res. 2007;22(2):166-76. https://doi.org/10.1093/her/cyl060.

31. Midhet F, Becker S. Impact of community-based interventions on maternal and neonatal health indicators: Results from a community randomized trial in rural Balochistan, Pakistan. Reprod Health. 2010;7(1):30. https://doi.org/10.1186/1742-4755-7-30.

32. Dzinamarira T, Mashamba-Thompson TP. Adaptation of a Health Education Program for Improving the Uptake of HIV Self-Testing by Men in Rwanda: A Study Protocol. Medicina. 2020;56(4). https://doi.org/10.3390/ medicina56040149.

33. Dzinamarira T, Mulindabigwi A, Mashamba-Thompson TP. Co-creation of a health education program for improving the uptake of HIV selftesting among men in Rwanda: nominal group technique. Heliyon. 2020;6(10):e05378.

34. Dzinamarira T, Muvunyi CM, Kamanzi C, Mashamba-Thompson TP HIV self-testing in Rwanda: awareness and acceptability among male clinic attendees in Kigali, Rwanda: A cross-sectional survey. Heliyon. 2020;6(3):e03515. https://doi.org/10.1016/j.heliyon.2020.e03515.

35. Dzinamarira T, Mulindabigwi A, Mashamba-Thompson TP. Co-creation of a health education program for improving the uptake of HIV self-testing among men in Rwanda: nominal group technique Under review. Heliyon. 2020.

36. Browne RH. On the use of a pilot sample for sample size determination. Stat Med. 1995;14(17):1933-40. https://doi.org/10.1002/sim.4780141709.

37. Chalmers TC, Levin H, Sacks HS, Reitman D, Berrier J, Nagalingam R. Metaanalysis of clinical trials as a scientific discipline. I: Control of bias and comparison with large co-operative trials. Stat Med. 1987;6(3):315-25. https://doi.org/10.1002/sim.4780060320.

38. Schulz KF, Chalmers I, Grimes DA, Altman DG. Assessing the quality of randomization from reports of controlled trials published in obstetrics and gynecology journals. JAMA. 1994;272(2):125-8. https://doi.org/10. 1001/jama.272.2.125

39. World Medical Association. World Medical Association: Declaration of Helsinki. Ethical principles for medical research involving human subjects. JAMA. 2013;310(20):2191-4. https://doi.org/10.1001/jama.2013.281053.

40. WHO. Guidelines on HIV self-testing and partner notification. Supplement to consolidated guidelines on HIV testing services 2016 [Available from: https://www.who.int/hiv/pub/vct/hiv-self-testing-guidelines/en/. Accessed on 13 July 2020

41. Pant Pai N, Sharma J, Shivkumar S, Pillay S, Vadnais C, Joseph L, et al. Supervised and unsupervised self-testing for HIV in high- and low-risk populations: a systematic review. PLoS Med. 2013;10(4):e1001414. https:// doi.org/10.1371/journal.pmed.1001414.

42. Lippman SA, Lane T, Rabede O, Gilmore H, Chen YH, Mlotshwa N, et al. High acceptability and increased HIV testing frequency following introduction of HIV self-testing and network distribution among South African MSM. J Acquir Immune Defic Syndr. 2018;77(3):279. https://doi.org/10. 1097/QAI.0000000000001601.

43. Oduetse OK, Nkomo B, Majingo N, Mashalla Y, Seloilwe E. Perceptions and attitudes towards acceptability of HIV self-testing among female sex workers in Selibe Phikwe, Botswana. Afr J AIDS Res. 2019;18(3):192-7. https://doi.org/10.2989/16085906.2019.1638427.

44. Gohil J, Baja ES, Sy TR, Guevara EG, Hemingway C, Medina PM, et al. Is the Philippines ready for HIV self-testing? BMC Public Health. 2020;20(1):1-8. https://doi.org/10.1186/s12889-019-8063-8.

45. Matovu JKB, Kisa R, Buregyeya E, Chemusto H, Mugerwa S, Musoke W, et al. 'If I had not taken it [HIVST kit] home, my husband would not have come to the facility to test for HIV': HIV self-testing perceptions, delivery strategies, and post-test experiences among pregnant women and their male partners in Central Uganda. Global Health Act. 2018;11(1):1503784. https://doi.org/10.1080/16549716.2018.1503784.

46. FHI360. NEPAL, TRANSGENDER PEOPLE IN: Linkages across the Continuum of HIV Services for Key Populations Affected by HIV (LINKAGES) Project. 2018. Available at https://www.fhi360.org/sites/default/files/ media/documents/resource-nepal-hivst-report.pdf Accessed on 3 July 2020

\section{Publisher's Note}

Springer Nature remains neutral with regard to jurisdictional claims in published maps and institutional affiliations. 